The summary and conclusions are a list of the working group's recommendations derived from their discussions outlined in the preceding chapters. These include the need for scientific soundness, quantification of risks versus benefits, limitations of nontherapeutic research to situations of minimal risk and parent and child consent issues. Draft rules for ethics committee organisation are also presented.

Obviously there are areas of controversy which will exercise those interested for many years. However, this report, as a distillation of so many man-hours of experienced thought, will act as a point of reference and balance in the tension between doing no harm to individual children and avoiding hindering essential research for the good of many children. In my opinion this book should be considered as essential reading for those who perform or supervise research involving children and for those who serve on ethics committees.

GRAHAM CLAYDEN

Senior Lecturer, Honorary Consultant Paediatrician, Paediatric Laboratory, Rayne Institute, St Thomas's Hospital, London SE1 7EH.

\section{The Healing Arts: A Journey Through the Faces of Medicine}

Ted Kaptchuk and Michael Croucher, 175 pages, London, £5.25, British Broadcasting Corporation, 1986.

The BBC published this book to accompany one of its major television series. I had not seen any of the episodes before writing this review, but the book is certainly readable in its own right.

It is written for the lay public but could well inform medical students and other aspiring health professionals who are generally taught little about the history of their own medical heritage, let alone how it compares and contrasts with that of other systems of medicine. It starts with a fairly objective if somewhat over-simple account of the philosophical bases of the major systems of healing and of some of the specific practices which are widely in use in the world today. It argues that, in its origins, the dominant system in the West - scientific medicine - was based on Greek thought, and had much in common with the systems still widely practised in China and India. It suggests that, although Western medicine has achieved much by its discovery of the part played by micro-organisms in disease and of methods to defeat them, it could achieve far more were it to acknowledge openly the ideas, still inherent in Eastern theories of illness, namely that ill-health is essentially a loss of balance and that the process of healing consists of restoring that balance.

In essence, the book is a plea to Western practitioners and patients to regard what is still likely to be dubbed 'fringe' medicine as 'complementary' rather than 'alternative'. Kaptchuk, who is responsible for the content of most of the book, trained in both Western and traditional Chinese medicine. He now directs a Pain and Stress Relief Clinic in Boston, USA. The large, eclectically-minded staff offer any one of 22 different regimens to those whose pain has not been satisfactorily controlled by orthodox Western medicine. He argues that effective therapy in every system of medicine is dependent upon the performance of rituals by the healers. The rituals vary from system to system, but they all work as magic does, that is by altering the perceptions people have of specific phenomena. In the case of healing, the sufferers have to perceive themselves as capable of overcoming forces responsible for their pain by strengthening the agents working to restore their balance. The imagery required to do that will depend upon the cultural heritage and assumptions of the sufferers.

The examples he chooses to illustrate his argument are drawn from many kinds of therapeutic situation. They include such diverse instances as the shaman's involvement of relatives in the treatment of illness among the Samoyed tribe in Arctic Siberia, the Simonton's 'guided imagery' fantasising techniques in cancer therapy in Dallas, Texas, and, in another Westernised setting, the effect of prescribing by an authoritative figure as compared to someone of lesser status. In each instance, it is fair to conclude that the healing occurred as a result of the sufferer's changed perception.

The message which the book sets out is not a new one, but it is elegantly stated and persuasive. Reviewing the book for the fournal of Medical Ethics it is appropriate to ask whether it raises any ethical issues. The authors do not suggest that ethical issues are raised when practitioners of scientific medicine refer their patients to practitioners of complementary healing procedures. Indeed, they advocate conventions of sorcerers and scientists!
Since most of the therapies are likely to be a good deal less invasive and potentially lethal than those with which orthodox medicine is frequently involved, it may be thought that ethical issues are not likely to arise. But it is pertinent to ask whether the conduct of doctors who seek to discourage patients from consulting practitioners, who are prepared to try to give them the help (the magic) which they are not receiving from orthodox methods, is ethical or unethical. Doctors are sometimes inclined to claim that they are protecting their patients from quacks. It is not always easy to accept that other healing rituals may be as or more effective than those which have become standard practice in the Western system of scientific medicine. This book may help that acceptance.

MARGOT JEFFERYS

Emeritus Professor of Medical Sociology University of London.

\section{Madness and reason}

Jennifer Radden, 174 pages, London, £5.95 paperback, George Allen and Unwin, 1985.

'Bad or mad' we say - so madness is excuse for wrongdoing. Ms Radden concerned with why this should be so. Consider the following syllogism:

'Peter is not responsible for his being mad.

If Peter had not been mad he would not have killed Paul.

Therefore Peter is not responsible for killing Paul.'

Ms Radden calls this argument the 'medical model' and demonstrates that it is false. The following counterexample shows why:

'Peter is not responsible for Paul calling him a fool.

If Peter had not been called a fool he would not have killed Paul.

Therefore Peter is not responsible for $N$ killing Paul.'

Ms Radden, therefore, rejects the idea $\omega$ that we may excuse a wrong act simply because it is caused by illness. For her it 0 is the effect of the madness on reasoning $\frac{}{\Phi}$ that is crucial. The question is not is he ill?', but 'how can he reason about the act'? And there are only two key factors $\overline{0}$ which underlie the excuse: ignorance $\frac{\vec{D}}{}$ and compulsion. If the madness is such $\frac{\rho}{\Phi}$ that the person is ignorant of why or $\stackrel{D}{2}$ how he acts, or if he is compelled to act, $\bar{\sigma}$ 
then the madness provides an excuse.

Ms Radden describes the case of a sniper who shot many people from the tower of the University of Texas before being kilied by the police. At autopsy he was found to have a brain tumour. Suppose that the tumour caused the sniper to hate people. Ms Radden believes that we would want to excuse the sniper on the grounds that although he may be able to give reasons for why he acted in that way (for example his hatred of people), he would be ignorant of his real reason for so acting (his tumour). On her view it is the ignorance of this real reason that is at the root of our excusing him.

But do any of us know the real reasons why we act as we do? Am I writing this because I like to think about philosophy, or to please the editor or because of a particular configuration of the chemicals and connections in my brain? Why does the brain tumour excuse, but my brain state does not? I suspect that we can only give an adequate answer in terms of an account of mental illness. The sniper is ill and I am not.

If this is true it undermines Ms Radden's position, because it would make her analysis of ignorance dependent on an analysis of illness. But her whole enterprise is to account for the excusing effect of madness without recourse to the concept of illness.

The same criticism can be made for the other pillar of her edifice: compulsion. If we are to say that one act is compelled by a person's mental state, but that another is not, we need to give an account of human action which can locate the essential difference. It is difficult to see how this could be done without involving the concept of illness.

My own belief, which I have come to only by reading this book, is that we must account for why madness may excuse wrongdoing through an analysis of madness as illness. This is the position which Ms Radden is out to attack. As in most good books on philosophy I found the examples more powerful than the arguments.

R A HOPE

Editorial Associate, Fournal of Medical Ethics, Wellcome Training Fellow in Psychiatry.
Which Babies Shall Live? Humanistic Dimensions of the Care of Imperilled Newborns

Editors, Thomas H Murray, Arthur L Caplan, 240 pages, Clifton, New Jersey, \$US34.50, Humana Press, 1985.

Making a decision about whether a neonate will live or die is both topical and emotive. How to determine criteria to establish exactly what decision should be made has much concerned practising doctors and ethicists, particularly in the past few decades. Which Babies Shall Live? makes no attempt to answer the question it sets, nor to resolve the dilemmas it poses. It is the result of a day-long seminar, organised by the Hastings Center, the Montefiore Hospital and Medical Center, and the New York Council for the Humanities, (no date supplied) concerned with 'taking a vacation ... from pretending to know the answers'. The organisers therefore turned to the humanities which, the editors tell us, have 'the deepest insights into the underground river of our ethos . . . I I am not sure they were right.

The contributors come from philosophy, bioethics, history, moral theology and literature (with one medical doctor thrown in to bring us up to date on neonatology). Some of the papers are slight, some out of touch with reality. Anyone who can talk about our judgements being 'temperated' as Margaret O'Brien Steinfels does, does not deserve to be read; and Leslie A Fiedler says of himself that he is 'more at home in the world of words and metaphor than fact, which is to say, an expert, if at all, in reality once removed'. His paper justifies this. Nevertheless, the editors see fit to have Ruth Macklin write a commentary on it. There are a number of commentaries but all on the less controversial or substantial issues. For example, there is no commentary on John D Arras's 'Toward an Ethic of Ambiguity', a paper which addresses itself to the extraordinary complexity of the whole issue of decision-making in the case of handicapped neonates; nor on Thomas H Murray's excellent discussion of suffering and neonatal intensive care.

Arras shows how difficult it is to establish 'the best interests of the child' and argues cogently that it is often not possible to judge whether life-saving procedures would be 'in the best interests of the child'. He considers that a better criterion is 'whether the child's impoverished level of existence is worth sustaining'. He shows that the 'issue is ... shot through with ethical ambiguity. Most anomalous children should be treated, some should be allowed to die. Substantive principles are available, but their application is fraught with difficulty and danger'. It seems to me that this book should have taken 'ethical ambiguity' as its title because in many cases that is what the contributors discuss.

Much of the volume is about the Baby Doe regulations of the US Department of Health and Human Services. These were formulated after a disputed decision not to treat a Down's syndrome neonate with a tracheo-oesophageal fistula and a possible heart anomaly. There is agreement in the book that a way to ensure treatment for Down's syndrome babies is necessary but it was felt that regulation was not the answer, and that, at any rate, the Baby Doe regulations were too narrow to be used for all possible neonatal handicaps.

Nancy Dubler discusses the right to privacy of patients about whom these decisions are being made. The problem, one which most of the authors tackle, is the right of an adult to make a decision about a neonate. She shows that the right of privacy has been 'bent and battered into supporting the concept that incompetent people must be protected from the rigid and mechancial imposition of medical care'. She provides no answers as to who should make these decisions although she makes clear who should not.

David H Smith seems to me to sum up the attitudes of many in this volume. 'We owe [a defective baby] respect and hope, care and comfort for his body, fair play and due process'. The trouble is we never find out what is fair play or due process.

The final section is somewhat more empirical as it is a report of a survey among health professionals about the treatment of the 'castastrophically ill newborns'. It deals with attitudes towards the US Department of Health and Social Security regulations about Baby Doe, and even though the final regulations came out after the survey was completed, the survey still makes interesting reading.

Caplan, in his conclusion, says that 'those who have carefully read through each of these papers may come away with an overinflated view of what the humanities can or ought be expected to 